\title{
LETTERS
}

\section{Increasing the transparency of clinical data}

We are writing to add Health Canada's perspective to recent commentaries published in CMAJ on the transparency of clinical trial data. ${ }^{1-3}$ Health Canada recognizes that access to clinical information can help health researchers and practitioners improve patient safety and health outcomes for Canadians.

Health Canada uses clinical data when making regulatory decisions on drug submissions and medical device applications. Clinical data in a submission can comprise tens of thousands of pages, including individual participant data. These data provide more comprehensive information on the safety and efficacy of health products than is currently publicly available elsewhere.

Health Canada is committed to greater openness and transparency and recognizes the value of sharing these data proactively at the right time and in alignment with international best practices. Along with other international regulators, including the European Medicines Agency and the US Food and Drug Administration, Health Canada is modernizing its approach in order to make more information publicly available.

As previous commentators have noted, opening up access to clinical data can have widespread benefits throughout the health care system. Enabling access would allow for the independent analysis of clinical data, which could in turn lead to a more complete understanding of the benefits and risks of health products, accelerate innovation by reducing the duplication of research, and increase the efficiency of drug development programs. Improving access to information increases accountability of Health Canada deci- sions and enables closer scrutiny of research findings.

Health Canada currently publishes several documents that provide the rationale for decisions related to drugs and medical devices. The Summary Basis of Decision ${ }^{4}$ and the Regulatory Decision Summaries 5 initiatives both improve access to information about decisions regarding the sale of certain drugs and medical devices in Canada.

The department intends to go further, and we propose to introduce regulations and supporting guidance to permit public release of clinical data in drug submissions and medical device applications after Health Canada has made a final regulatory decision. Clinical data would be treated as confidential business information during Health Canada's review process, including appeal or reconsideration of a decision, but would no longer be considered confidential business information following the completion of the review. This helps to protect commercial confidentiality at critical points in the development and assessment of drugs and devices. In addition, specific categories of clinical information that may have ongoing commercial value following a regulatory decision (e.g., proprietary test methods) would be permitted to be exempted from public release.

Health Canada has published its proposal as a white paper for public comment. ${ }^{6}$ Interested parties have 75 days to provide comments. We encourage all interested parties to review our proposal and to provide feedback. Your input is invaluable. Health care professionals, clinicians and academics have shown the greatest interest in broadening access and have considerable insight to share.

Over the coming months, we will consult closely with industry, researchers, health professionals and patient groups to inform the development of regulations and implementation of this proposal. Health Canada recognizes that a shared approach by industry and government that facilitates greater access to clinical information can assist health researchers and practitioners and contribute to improved patient safety and better health outcomes for Canadians.

We commend CMAJ for its attention to this issue, and look forward to further dialogue on Health Canada's approach to increasing the transparency of clinical data.

\section{Pierre Sabourin MBA}

Assistant Deputy Minister, Health Products and Food Branch, Health Canada, Ottawa, Ont.

\section{Supriya Sharma MD MPH}

Chief Medical Advisor, Health Canada, Ottawa, Ont.

Cite as: CMAJ 2017 March 27;189:E473. doi: $10.1503 / \mathrm{cmaj} .170271$

\section{References}

1. Wieseler B, McGauran N. Secrecy or transparency? CMAJ 2017;189:E185-6.

2. Herder M. Reinstitutionalizing transparency at Health Canada. CMAJ 2016;188:218-9.

3. Persaud N, Doshi P. North American regulatory agencies can and should make clinical trial data publicly available. CMAJ 2016;188:96-7.

4. Drugs and health products: Summary Basis of Decision. Ottawa: Health Canada; [updated 2016]. Available: www.hc-sc.gc.ca/dhp-mps/ prodpharma/sbd-smd/index-eng.php (accessed 2017 Mar. 10)

5. Drugs and health products: Regulatory Decision Summaries. Ottawa: Health Canada; [updated 2016]. Available: www.hc-sc.gc.ca/dhp-mps/ prodpharma/rds-sdr/index-eng.php (accessed 2017 Mar. 10)

6. Public release of clinical information in drug submissions and medical device applications [white paper]. Ottawa: Health Canada; 2017. Available: www.canada.ca/en/health-canada/ programs/public-release-clinical-information-drug -submissions-medical-device-applications.html (accessed 2017 Mar. 13).

Competing interests: None declared. 